\title{
Engagement as a Core University Leadership Position and Advancement Strategy: Perspectives from an Engaged Institution
}

Received (in revised form): June 14, 2007

\section{Mark N. Langseth}

is Assistant Vice President for University Development at Portland State University, and former Executive Director of Minnesota Campus Compact, a non-profit organization dedicated to promoting civic engagement in higher education.

\section{Cassie S. McVeety}

is Vice President for University Relations at Portland State University and serves on the board of trustees for the Council for Advancement and Support of Education (CASE).

\section{Abstract \\ Over the past decade, Portland State University (PSU) has received consistent national accolades for its innovative, engaged approaches to student learning. More recently, PSU has expanded its emphasis on engaged research and has more intentionally highlighted its institutional partner- ships and impact on the region. A current (2006-07) university-wide}

\footnotetext{
Author's Contact Address:

Mark N. Langseth

Portland State University

P.O. Box 751, Portland,

OR 97207-0751, USA

Phone: +1503 7258797

Fax: +1 5037254499

Email: langseth@pdx.edu
}

planning process has, for the first time, explicitly established "engagement" in learning, in scholarship, and in institutional partnerships as PSU's “core leadership position." As such, engagement will guide university goal setting, budgetary decisionmaking, and priorities for PSU's next capital campaign. This paper discusses the evolution of PSU's commitment to engagement and current and future implications for fund raising at PSU and beyond.

International Journal of Educational Advancement (2007) 7, 117-130. doi:10.1057/palgrave.ijea.2150052

\section{Keywords:}

leadership, public engagement, advancement, fund raising 


\section{Introduction}

Any successful advancement effort around engagement should be deeply informed by one's specific institutional context. This point is critically important because institutions vary in their interpretation and capacity to carry out engagement activities. Holland (2005) suggests that institutions develop their own unique approaches to engagement by "adopting the notions of civic engagement and engaged scholarship according to the relevance of those concepts to their particular institutional mission and capacity" (p. 242). Recognizing the importance of institutional context, our paper focuses on one urban institution, Portland State University (PSU), and examines how engagement has defined its past and is shaping its future.

We begin with a summary of the historical and geographical context in which PSU's commitment to engagement evolved. We offer this story of PSU not as a script for how engagement should evolve, but rather as an invitation for advancement officers to consider how they might describe their own institutional story around engagement, both universitywide and in the specific context of development. Building on this historical context, we then discuss more contemporary strategies PSU has employed regarding engagement, and conclude with some thoughts regarding the larger engagement movement in higher education and in advancement, including how this larger movement might inform advancement efforts across the country. Embedded throughout is discussion regarding PSU's evolving definition of "engagement."

\section{Historical and Geographical Context}

\author{
The early years (1946-51)
}

PSU's experience with engagement has roots in the very founding of the institution just over 60 years ago. When Portland State's predecessor institution, the Vanport Extension Center, was founded in 1946, it was through the leadership of community members and educators who recognized the needs of World War II veterans to have access to a high-quality college experience. Community need as a guiding force has continued as a defining theme for the institution through Vanport's transformation into Portland State College, into a comprehensive University, and now into its seventh decade of serving a growing and diverse urban population.

Starting a new college campus in the state of Oregon was a daunting challenge in the mid-1940s as six other public higher education institutions already existed throughout the state (although none were located in the population center of Oregon's largest city, Portland). Opposition from some political figures, the established and traditionally formed residential campuses of University of Oregon and Oregon State University, and other detractors may have proven insurmountable to the early founders of Portland State had it not been for the substantial community advocacy and support. Working closely together in the early years, campus and community leaders came to the conclusion that a university formed not just for returning war veterans but as a way to meet a broader community need, was a concept that had multiple 
benefits to the students, the workforce and the economy of the region as a whole.

When a devastating flood destroyed the Vanport Extension Center and all surrounding areas in May of 1948, hundreds of books were donated by local and national individuals and institutions to rebuild the library for students and faculty. What has now been recognized as the first private donations to the institution, these gifts of library books numbered over 1,600 volumes and included a signed collection of the works of Nobel and Pulitzer prize winning author Pearl Buck, who was motivated to give a collection of her works to help the students whose institution was literally swept away in the flood. Similar unsolicited donations marked PSU's first 15 years. These early expressions of private support were grounded in the larger context of community-based support that surrounded PSU in its founding years, and helped lay the groundwork for garnering additional private support in the future.

In these early years, engagement at PSU was not formally defined, but was actualized primarily along three lines. First, engagement was local. PSU's focus was on meeting a specific local need (workforce training) by serving a particular local constituency (returning veterans). Second, engagement was survival focused. PSU's initial commitment to engaging with its local community was focused on surviving the critical founding years. Third, engagement was two-way. The 1948 flood provided an early opportunity for the Portland community to engage with PSU as the University created programs to meet community needs.

\section{Growth on the Park Blocks} (1952-89)

In fall 1952, PSU's relocation to the "Park Blocks" area in the heart of downtown Portland became official with the beginning of classes in Old Main, PSU's first purchased building and a former high school. Throughout the next decades of growth and transformation, what started as an extension center for continuing education for veterans evolved into Portland State College. The young College then struggled with the challenges of expanding academic and student offerings including graduate programs and degrees. As Dodds (2000) notes in his book, The College That Would Not Die, the leaders of the institution built degree programs and offerings via a highly collaborative process with students as well as the community. Portland State College advanced towards university status by taking advantage of what it already recognized as a powerful asset: enormous community support for this fledgling institution.

Like the initial founders, early presidents of Portland State College cultivated relationships with powerful groups in the Portland business and civic community to help convince influential individuals in government and business that the development of graduate degrees and transition to university status were vital for the community as a whole. For example, President Branford Millar (1959-68) recognized that cultivating broader collaboration with the business community was critical to Portland State's aspirations to become a vital partner and an anchor institution supporting Portland's economic, social, and civic growth. 
As Dodds (2000) recounts, Millar's early efforts to cultivate close business and community ties ultimately proved highly successful. The vocal advocacy of community leaders from the City Club, Port of Portland, Pacific Power and Light, the Portland Chamber of Commerce and others-all of whom testified in support of Portland State's addition of graduate degrees and thus university statuswas enormously helpful to the college gaining university status in 1969. This support facilitated the expansion of facilities from one to 26 buildings by 1969, and enrollment growth from 10,000 students in 1969 to over 15,000 by 1989 (and set the stage for even further growth to our current enrollment of 25,000).

As PSU grew downtown, both in its physical presence and in its partnerships, so did its perspective on engagement. Somewhat paradoxically, during this period, engagement became even more localized, as we put down roots in a particular geographic setting and deepened our associations with downtown constituencies. At the same time, PSU became more geographically expansive, as we transitioned to broader university status, as students from outside Portland began enrolling in far greater numbers, and as we created innovative international educational programs.

\section{Let knowledge serve the city-and beyond (1990-2006)}

Portland State has seen continued growth in programs, students, alumni, and campus physical presence throughout the 1990s and into the early 2000s. Conversely, state government support for higher education in Oregon, which began eroding in the 1980s, continued with even greater declines in the next two decades. As a result, tuition and private fund raising began to assume an ever-greater role in securing continued growth and development. In addition, leaders began to recognize the importance of identifying particular attributes and strengths that helped establish PSU as a desirable institution and as distinctive from its peers and competitors.

It was during this period that PSU began articulating more publicly a recognition of its urban mission, including crafting the motto for the campus that stands today: "Let Knowledge Serve the City." Perhaps the most significant programmatic development in the University's current commitment to engagement came in the early 1990s when a new curriculum called "University Studies" was formed. The University Studies curriculum, still in place today, provides students with a coherent and cohesive program of integrated learning experiences, including a significant emphasis on community-based learning. The culmination of the University Studies program, required for all undergraduates, is a six-credit communitybased learning capstone course designed to give students opportunities to use the knowledge they have gained in the classroom to address a "real-life" challenge identified by a community partner. Students in all fields of study form interdisciplinary teams to address these challenges and provide tangible results to community partners. 


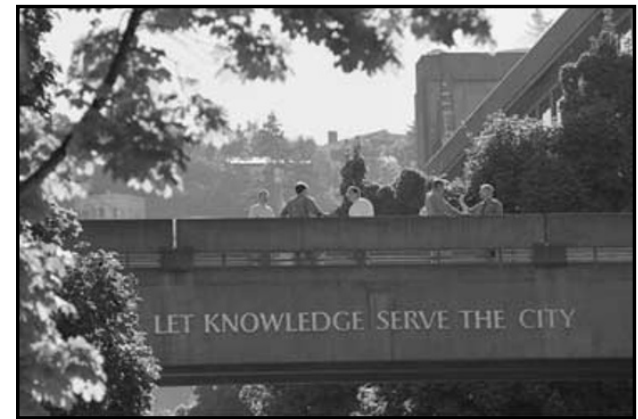

In the same spirit of broadening educational horizons for students, PSU also significantly strengthened its commitment to both diversity and international perspectives, particularly during the last ten years (1997-2007). Presidential initiatives emphasizing diversity and international education have resulted in an impressive array of cultural, social, economic, and academic programs, most of which are closely linked to regional and local community groups. Intentional global perspectives have been added throughout the curriculum and PSU is committed to sending more students abroad, offering more international opportunities for community engagement, and attracting more students from outside the US.

As engagement in teaching and learning broadened and deepened, so did institutional commitment to research, with particular emphasis on engaged research. Importantly, as PSU moved toward a more engaged approach to both teaching and to research, we also modified our promotion and tenure guidelines to provide faculty rewards for engagement. During this same period, PSU began to receive significant external accolades for our increasingly intentional focus on engagement, including:

- US News \& World Report's “America's Best Colleges" ratings for five straight years (2003-07) in five separate categories: first-year experiences, service-learning, internships/co-ops, learning communities, and senior capstone;

- Princeton Review's 2005 “Colleges with a Conscience: 81 Great Schools with Outstanding Community Involvement";

- New England Board of Higher Education's "Saviors of Our Cities" award recognizing 25 US universities (2006);

- selection as an inaugural institution in the Carnegie Foundation for the Advancement of Teaching's new "community engagement" classification (2006).

In addition, current and past PSU leaders have assumed important leadership roles in many national and international efforts to expand engaged teaching and learning, including directing the Corporation for National and Community Service's National Service-Learning Clearinghouse, co-founding the groundbreaking Clearinghouse and National Review Board for the Scholarship of Engagement, and providing consultation all over the world, including recent work with Australian leaders to bring engagement into the mainstream of the entire Australian higher education system.

Although PSU had not yet fully defined institutional "engagement," by 2006 four clear pieces of our engagement puzzle had clearly emerged. Engagement was now seen 
widely on campus as encompassing four core elements:

(1) A more public, intentional institutional value.

(2) A central pedagogical tool for teaching and learning.

(3) An important element of research and of faculty promotion and tenure.

(4) Both a local/regional and a national/international endeavor.

In 2006, PSU initiated a comprehensive institutional report on community economic impact, "Our University," which captured PSU's multiple forms of student, community, and institutional engagement and documented the myriad of ways PSU contributes to the economic, social, civic, and environmental qualities of life in Portland. Together, all of these commitments add up to over $\$ 1$ billion in annual economic impact on the Portland metropolitan area.

Importantly, this report essentially expanded PSU's definition of engagement beyond teaching/learning and scholarship, beyond students and faculty. Specifically, this report included documentation of our role as employer, purchaser, student aid provider, real estate developer, work force developer, community partner, business accelerator, and expert advisor.

\section{Engagement as Core Leadership Position (2006-07)}

While all of our recent external recognition and dissemination of expertise and information regarding engagement has certainly helped raise the institution's profile externally, it has been equally valuable in helping our internal community crystallize around the term "engagement." Specifically, during the 2006-07 academic year, the Provost, along with a duo of consultants, led a comprehensive strategic planning process involving the entire university community. With remarkable ease, university leaders arrived at engagement as PSU's "core leadership position." The term, core leadership position, refers to the distinctive strength that already permeates the University and an integrating theme that will guide decisions about future strategic priorities and budget allocations.

Perhaps even more remarkably, no substantive opposition to this core leadership position was voiced in two related university-wide planning forums, each involving over 200 members of the university community. Although we had not yet formally chosen the word "engagement" as the most fundamental descriptor of our identity, engagement was already widely understood in this way.

Although the planning process continues as this paper goes to press, as of spring 2007, we have currently defined engagement as "our collaborative approach to exchanging knowledge and resources with local, regional, national, and global partners for mutual benefit of students, faculty, and the community. It contributes to learning and scholarship that is globally relevant and regionally focused." Equally important, through the planning process, we defined three forms of engagement-engaged learning experiences, engaged research, engaged institution-to help clarify what we meant by engagement, to 
solidify the broad scope of our core leadership position, and to guide the development of strategic priorities:

(1) Engaged learning experiences: Portland State students participate in engaged and transformative learning experiences in which they build the knowledge, skills, values, and motivation for making a positive difference in both their own lives and in their communities.

(2) Engaged scholarship: Engaged scholarship emerges from learning and discovery in collaboration with communities. It engages faculty in academically relevant work that simultaneously meets campus mission and community needs: a scholarly agenda that integrates communities' assets and interests. Engaged scholarship generates, transmits, integrates, and applies knowledge through collaborations designed to contribute to the public good.

(3) Engaged institution: Engagement describes the collaboration between Portland State and its larger communities (local, regional, national, global) for the mutually beneficial exchange of knowledge and resources in a context of partnership and reciprocity. Through its engagement, Portland State creates and transmits knowledge with meaning and ensures relevant and authentic teaching and learning experiences.

Figure 1 illustrates how PSU currently conceives of its core leadership position and its relationship to these three core elements of engagement.

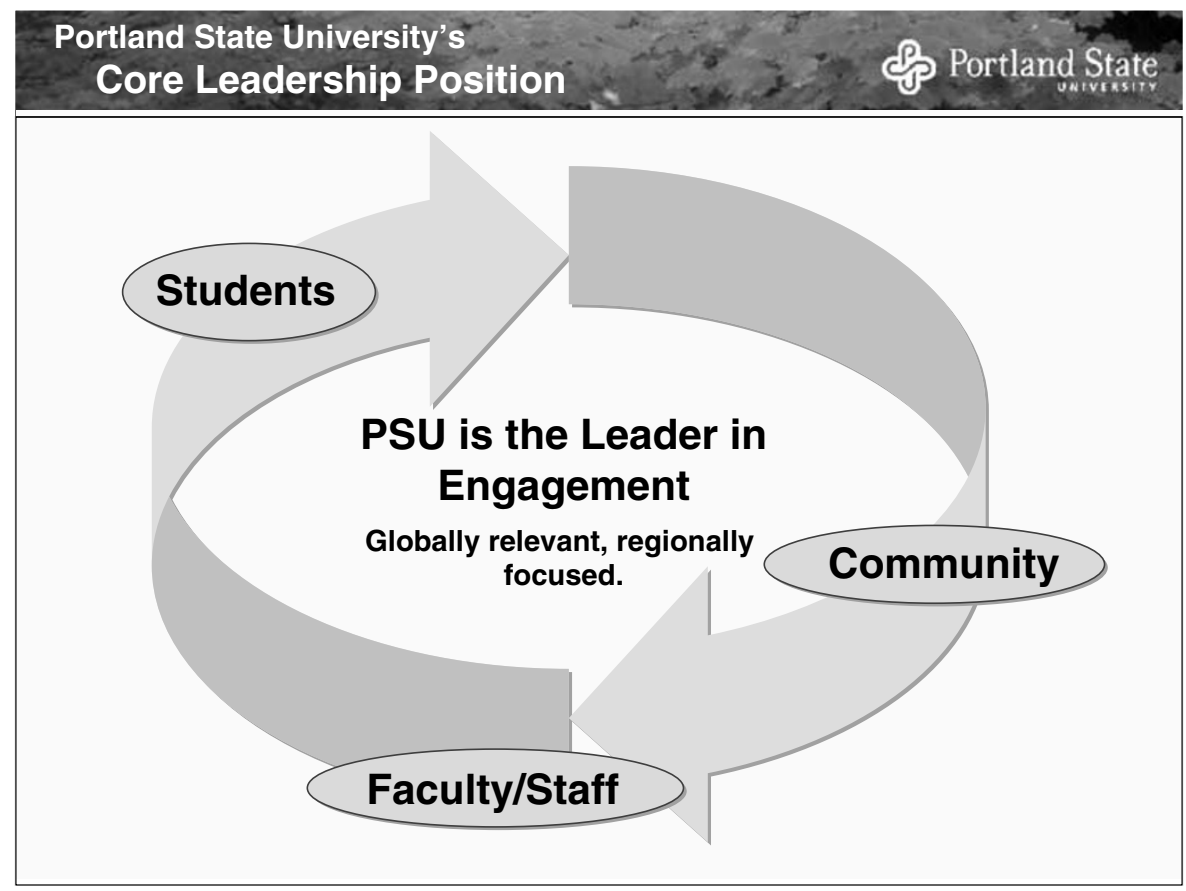

Figure 1: Portland State University's core leadership position 
Again, this core theme of engagement will provide overall guidance as we finalize strategic priorities, programs for growth, and related budgetary decision-making.

\section{Implications for Advancement}

As outlined above, engagement has been a way of life for PSU since its founding in 1946, and has grown consistently in breadth and depth over the past 60 years. More recently, it has been clearly defined and embraced as "core leadership position" via a 200607 university-wide strategic planning process. Let us now turn our attention to how this commitment to engagement has informed and continues to inform PSU's approach to advancement. In the following paragraphs, we only briefly discuss marketing, communications, and alumni relations related to engagement. Instead, we focus most of our attention on how PSU's commitment to engagement influences our efforts to raise private financial support for the university.

\section{History and Context}

Like many US state universities, PSU's entry into the world of private fund raising came gradually. As cited above, the university's first private donations came in response to a devastating flood that destroyed the physical campus just two years after its founding. This in-kind contribution of over 1,600 books to help rebuild the library's collections, and thereby to help save the campus, is an apt beginning to our development story at PSU. That is, with now less than 15 percent of our core operating budget provided by the State of Oregon, PSU relies even more heavily today on state and federal grants and on generous private donors to enable us to survive and thrive.

Also like many US state universities, for its first few decades, PSU had no formal development infrastructure to coordinate identification, cultivation, and solicitation of private donations. Rather, such efforts were more piecemeal in nature, responding to needs and opportunities as they arose. By the 1980s, it became clear that a more intentional, more structured approach to fund raising was needed to help advance the university's priorities. But it was not until the 1990s that the university began investing significantly in building a university-wide infrastructure for private fund raising, including adding development staff in each of the university's seven academic units, in athletics and in the library. This growth was spurred by an increasing realization that private donations would play an increasingly important role in ensuring a bright future for PSU.

\section{An Inaugural Comprehensive Campaign}

By the late 1990s, it became clear that the rapid growth and continued aspirations of the university demanded a more rapid and comprehensive approach to private fund raising. The prospects remained dim for state funding adequately fueling growth, a critical mass of private donors had demonstrated sustained interest in PSU, and projections for continued rapid population growth in the Portland area all pointed to the need for an expanded approach to fund raising at PSU. The time had come for our first comprehensive campaign. 
The silent phase for "Building Our Future: The Campaign for Portland State University" began in 1999 with a feasibility study that indicated a realistic fund raising goal of $\$ 75$ million. This campaign was truly comprehensive in nature and included overall goals similar to those heard in campaigns throughout the country: producing the engineers, scientists, and research our economy demands; preparing the teachers who will educate our children and grandchildren; training the professionals who strengthen our family systems; meeting the demands of business in a climate of rapid innovation, changing technology, and a global marketplace; and creating thoughtful citizens and enriching cultural life through the humanities and the fine and performing arts.

The campaign was launched with a goal of $\$ 90$ million, and the goal was expanded to $\$ 100$ million when the campaign was publicly announced in October of 2004. When the campaign concluded in June of 2006, PSU had raised almost $\$ 114$ million to support programs, people, and projects in every unit of the university.

While typical university fund raising relies heavily on alumni supportparticularly in traditional US residential universities-PSU's first campaign was built on the support of community members as significant donors, which could be viewed as a tangible sign of the effect of engagement on philanthropic support of the institution. To illustrate, there were two lifetime donors of $\$ 1$ million or more to PSU prior to the campaign, and at the close of "Building Our Future," there were 27. Of those, four donors were PSU graduates, while the vast majority were community-based individuals and organizations. To quote one couple about their major gift commitment to PSU: "We didn't attend Portland State, but we're enrolled in its vision." Strong community partnerships and intentional engagement with influential community leaders were the hallmarks of PSU's founding and now its fund raising philosophy and practice as well.

Several projects funded through this first campaign also exemplified PSU's commitment to engagement overall and to engagement as a fund raising methodology. For example, one of the prominent capital projects in the campaign was a new Native American Student and Community Center. The center was a truly collaborative project that included student groups, a number of regional tribes and tribal associations, the Native American community, and the University. Because the University was already heavily engaged with these various entities, the collaborative fund raising that occurred to fund the facility was a natural outgrowth of the real partnerships that already existed. Various funders, including many foundations, applauded PSU's collaborative approach to this project and to others funded through the campaign, citing the increased leverage and success afforded by this highly engaged approach to fund raising.

\section{Engagement and the Next Campaign}

Soon after the completion of "Building Our Future," PSU President Dan Bernstine began referring to this campaign as a "warm up," alerting the development staff that he envisioned a 
much larger effort on the horizon, on the magnitude of \$200-\$250 million. Indeed, the elements that led us to our first campaign-outgrown facilities, need for improved faculty recruitment and retention, scholarship support for students, and expanded need for higher education in a fast-growing metropolitan area-were still there at the end of our inaugural campaign. Moreover, the gap between the institution's ever-growing aspirations and its limited resources-though narrowed by the first campaign-was still large and projected to grow even further without another big jump in private donations.

While this need to close the gap between aspirations and resources had not changed since the completion of our first campaign, the need to attract a more diverse pool of donors to PSU had. Like many of our peers, we had developed special relationships with a core group of generous donors who have given time and time again to a variety of programs to advance PSU. In fact, it was largely through this core group's steadfast commitment that we were able to meet and exceed our goals for "Building Our Future." But clearly, even with expanded support from these pioneering and mostly community-based donors, the opportunity to reach new donors and investors must be more thoroughly explored as we look to the future. Our growing body of more than 110,000 PSU alumni, approximately two-thirds of whom reside in the Portland metropolitan area, provide a particular opportunity for new donor growth. At the same time, we will continue our tradition of attracting community donors who are enrolled in our vision of an engaged institution.

\section{Clear direction, big ideas}

As any good university advancement professional knows, step one in an ideal campaign planning process is for the university to arrive at a clear consensus around core leadership position and strategic priorities. Fortunately, PSU has done just that through the intensive 2006-07 university-wide planning process described above. Even more fortunately from a development perspective, the University is now poised to more publicly proclaim "engagement" as its core leadership position.

Moreover, it is clear that engagement has emerged as an attractive proposition for potential donors to US higher education. For example, in 2004, Campus Compact, a national coalition of over 1,000 college presidents committed to engagement, documented over 70 endowed centers for community and public service centers in its booklet entitled, The Service and Service-Learning Center Guide to Endowed Funding. The booklet reports that some of these centers are endowed with gifts of several million dollars (Campus Compact, 2004). Since this booklet was released, we are aware of several additional gifts of large engagementrelated endowments, including a recent $\$ 30$ million gift to Duke University.

Unlike our first campaign, with a more generic "Building Our Future" tagline and a somewhat typical set of comprehensive campaign goals, PSU is now positioned to think more boldly about how this clear direction for the university around engagement can be leveraged into more innovative, compelling campaign themes and more ambitious ideas that will 
simultaneously advance PSU and the region.

Fortunately, this engagementoriented direction is not something that will be a surprise to leaders outside the university, particularly those close to the first campaign.

Although the theme for that campaign was quite broad, the language used to introduce the campaign was anything but. Our final campaign brochure, for example, began with: "Forget the ivory tower. PSU thrives in the heart of the real world." Although we did not employ engagement as a core theme, once again, it is clear that engagement was at least informally understood as central to our identity.

How exactly the university's more formalized commitment to engagement as core leadership position will inform future campaign priorities remains to be seen. But we believe that engagement as overarching theme holds great promise to help attract new donors who want to invest in something that benefits the larger community in tangible ways via the university. In this special issue, Shelley Strickland's article examining the motivations of transformational donors provides evidence to support this claim.

Equally important, we believe that prospective donors will respond well to the university's more public proclamations of our commitment to engagement. After all, donors are community members with community concerns. The more tightly we can weave together university and community interests, the more successful we will be in attracting donors. To the extent that fund raising is a profession of matchmaking between donor/community interests and university priorities, we believe our newly formalized commitment to engagement bodes well for our next campaign.

\section{Engagement as a process for fund raising}

While our inaugural campaign spurred a significant increase in volunteers helping to lead fund raising at PSU, our next campaign will need to engage volunteers in a much more expansive way. Both at the academic unit level and in university-wide roles, additional volunteer energy must be mobilized to lead various aspects of the next campaign. We will derive this additional energy by further motivating and training current volunteers and by recruiting and training additional volunteers.

This process has already begun. Specifically, we are currently conducting one-on-one conversations with key current volunteers to inform them about the university's new core leadership position around engagement and to seek their feedback, thereby engaging them in the early stages of campaign planning. We have worked closely with the Provost, who is leading the university-wide planning process to determine the appropriate time for soliciting this feedback, and we will, of course, share feedback we receive for consideration as the planning process continues. In order to maximize volunteer participation, we have also begun conversations about how we might design the committee structure for the campaign. Whereas our inaugural campaign enlisted a campaign steering committee and a Foundation board campaign committee, we anticipate creating 
several volunteer committees to play various roles in the upcoming campaign. This increased commitment to engaging volunteers seems fitting as we embark on a campaign that mirrors the university's new overall theme of engagement, and we will need this increased volunteer power if we are to succeed in reaching our more ambitious campaign goals.

\section{Engagement as advancement leadership opportunity}

As PSU's central office fund raising staff engaged in a strategic planning process of our own for 2007-08, an interesting development occurred regarding our departmental engagement in the community. That is, as we were considering how our department might demonstrate engagement in the community, we determined that PSU's fund raising staff should play a role in "raising the bar" for philanthropy in Portland. That is, in order to live up to the institution's aspirations regarding engagement, we believe that we must play a highly collaborative leadership role in increasing philanthropy in the community at large. We asked, "If not us, who will play such a leadership role?" The fact that this question even arose in the way it did is evidence that PSU has arrived as one of Portland's anchor institutions, as envisioned so long ago, and thus our goals must be broader as well.

The implication of assuming this fund raising leadership role is that our next campaign will not only be a campaign for PSU, but that we will also engage a larger collaborative campaign with interested philanthropists, community and nonprofit organizations to inspire evergreater philanthropy to all worthy causes in the Portland area. Essentially, we determined that we must do our part to reflect the institution's more formal commitment to engagement. Taking leadership in our professional field of philanthropy in such a way that would benefit both PSU and the larger community seemed the most appropriate way to actualize this commitment in our fund raising operation.

\section{Implications beyond PSU: What's your story?}

Again, we offer the story above regarding the evolution of PSU's commitment to engagement, both as an institution and in our fund raising operation, not to suggest that our way is the way, but rather to illustrate the importance of context as one thinks about how engagement and advancement best intersect at a given institution. What's important is not our particular story, but rather, yours.

Questions development professionals might ask about institutional context might include:

- What elements of engagement were present at the founding of your institution?

- How and why have those elements changed over time?

- How is engagement expressed now within the institution?

- Is the term "engagement" the most useful way to express the institution's commitment to community and partnership, or is there a different term more appropriate to the specific institutional history and the larger context in which the institution operates? 
- How do the future aspirations of the institution align with an increased emphasis on engagement and an increased intersection between engagement and advancement?

Questions development professionals might ask about the fund raising context include:

- What projects or programs at our institution might be considered highly "engaged" and to what extent has the advancement operation assisted these programs in raising funds?

- To what extent are our development professionals aware of all "engaged" programs on campus and of how they might assist in their growth and development?

- How has our institution's advancement operation exemplified engagement in the way in which we do our work? Why and how might we further employ engagement as a process for our work?

- Why and how might development professionals engage with other educational institutions, nonprofits, or NGOs on common projects to enhance philanthropy in our local community?

\section{Engagement as Trajectory for Higher Education and for Advancement}

Because of PSU's long-standing commitment to engagement and our recognized leadership in the US, we have been privileged with a front row seat to watch the evolution of the engagement movement in US higher education and beyond over the past 20 years. We offer the following final thoughts from this vantage point in hopes that they might embolden others to consider engagement as a guiding force to advance their colleges and universities.

\section{A global engagement movement} Campus Compact, referenced earlier as a coalition of over 1,000 US college and university presidents committed to engagement, grew almost tenfold in just its first 20 years. Starting in 2000, this organization began to receive consistent inquiries from countries across the globe interested in expanding their commitment to engagement in higher education. Vietnam, South Korea, South Africa, Europe, and Australia were some of the first nations to express interest. Several more have followed, and subsequent partnerships and exchanges have proven-in the reciprocal spirit of engagement-mutually beneficial. As so many aspects of life in the 21st century become global, the internationalization of the higher education engagement movement is a particularly important development and one that bodes very well for engagement's long-term viability. In short, we view engagement as a fundamental element of higher education in the new global era.

\section{A more engaged approach to advancement}

Likewise, as colleges and universities all over the world express more interest in cutting edge fund raising strategies, engaged approaches to fundraising have become increasingly important. While staff leadership in the fundraising process will undoubtedly continue as a critical element of 
any successful operation, strategic mobilization of volunteers must play a more central role if colleges and universities expect continuous improvement in their development results. In the context of the broader movement toward engagement in higher education, a renewed commitment to engagement in the fundraising process seems a wise choice for advancement professionals.

Finally, in the spirit of collaboration and engagement, we believe there is great promise for mutual benefit when those on campus leading engagement programs and those on campus leading advancement efforts join forces. Advancement professionals eager for new opportunities to interest donors in their universities will find partnerships with engagement programs profitable. Engagement professionals, often eager for additional support for their important initiatives, will find partnerships with advancement professionals equally profitable. Together, we can both advance the larger agenda of engagement in higher education and the need for higher education to offer to donors attractive options for investments in programs that make a real difference in communities.

\section{References}

Campus Compact (2004), The Service and ServiceLearning Guide to Endowed Funding, Campus Compact, Providence, RI.

Dodds, G.B. (2000), The College that Would Not Die: The First Fifty Years of Portland State University, Oregon Historical Society Press, Portland, OR.

Holland, B.A. (2005), "Institutional differences in pursuing the public good", in A. J. Kezar, T. C. Chambers and J. C. Burkhardt (eds.), Higher Education for the Public Good: Emerging Voices from a National Movement, Jossey-Bass, San Francisco, pp. 235-260. 